\title{
COMPONENTES DO RENDIMENTO, TEORES DE ISOFLAVONAS, PROTEÍNAS, ÓLEO E QUALIDADE DE SEMENTES DE SOJA ${ }^{1}$
}

\author{
MARIZANGELA RIZZATTI ÁVILA ${ }^{2}$, ALESSANDRO DE LUCCA E BRACCINI ${ }^{3}$, CARLOS ALBERTO SCAPIM ${ }^{3}$; \\ JOSÉ MARCOS GONTIJO MANDARINO ${ }^{4}$; LEANDRO PAIOLA ALBRECHT ${ }^{2}$ E PEDRO SOARES VIDIGAL FILHO $^{5}$
}

\begin{abstract}
RESUMO - A soja, além de ser utilizada na alimentação animal vem sendo incluída na alimentação humana, pois possui na sua composição química, proteínas, lipídios, algumas vitaminas e compostos polifenólicos, como as isoflavonas. A atividade antioxidante das isoflavonas pode ser considerada um mecanismo de garantia da qualidade das sementes, em virtude da teoria de deterioração, em detrimento da ação de radicais livres na membrana celular. Desta forma, conduziu-se um experimento durante o ano agrícola de 2004/05 em dois locais de semeadura (Maringá e Umuarama), com o objetivo avaliar os componentes de produção, a qualidade fisiológica das sementes de soja produzidas em dois locais de semeadura e determinar os seus teores de óleo, proteínas e de isoflavonas, bem como correlacionar o conteúdo de isoflavonas com os componentes de rendimento, qualidade fisiológica, teores de óleo e proteínas das sementes de soja. As cultivares estudadas foram de ciclo precoce (EMBRAPA 48 e BRS 213) e semiprecoce (BR 36, BRS 133, BRS 184 e BRS 214). Avaliou-se o rendimento e a massa de mil sementes, a qualidade das sementes por meio dos testes de germinação (primeira contagem e contagem final), tetrazólio (vigor e viabilidade) e o teor de óleo, proteínas e isoflavonas. Verificou-se que as cultivares BRS 133 e EMBRAPA 48 apresentaram os maiores conteúdos de isoflavonas, ao passo que, para a cultivar BR 36, foi constatada a menor quantidade, em ambos os locais. Para todas as cultivares avaliadas em Maringá, a germinação das sementes foi superior a $80 \%$. A correlação entre isoflavonas e massa de mil sementes foi negativa para as duas localidades.
\end{abstract}

Palavras-chave: Glycine max, malonil, germinação, vigor.

ISOFLAVONE, PROTEIN AND OIL CONTENTS AND SOYBEAN SEED QUALITY

\begin{abstract}
Soybean seeds have been used not only for animal, but also for human nutrition because of the presence of proteins; lipids; some vitamins and polyphenolic compounds, such as isoflavones, in their chemical composition. The antioxidant activity of isoflavones may be considered a safe mechanism of seed quality. This is due to the deterioration theory which leads to a cellular detriment because of the action of free radicals on cell membranes. Experiments were carried out during the 2004/05 agricultural year in two different sowing locations (Maringá and Umuarama). The objective of this study was to evaluate the yield, physiological quality of seeds produced in two sowing locations; to determine oil, protein and isoflavone contents; as well as to correlate isoflavone contents to the yield, physiological quality and oil-protein contents of soybean seeds. The seed quality was evaluated by the germination test (first count and final count); the tetrazolium test (vigor and viability) and the concentration of oil, protein and isoflavone tests. Analysis of the isoflavone contents showed that the BRS 133 and EMBRAPA 48 cultivars presented the highest isoflavone contents whereas the BR 36 cultivar showed the lowest isoflavone contents in both places. Germination was above $80 \%$ in all cultivars tested in Maringá. The correlation between isoflavones and the weight of one thousand seeds was negative for both locations.
\end{abstract}

Key Words: Glycine max, malonil, germination, vigor.

1 Submetido em: 03/10/2006.Aceito para publicação em: 14/06/2007.

2 Eng. Agrônoma (o), Prof. Adjunta do Depto. De Agronomia, Universidade Estadual de Maringá. Estrada da Paca s/n. São Cristovão, 87507-190, Umuarama, PR.e-mail: marizangela_rizzatti@ hotmail.com; e-mail: lpalbrecht@yahoo.com.br

3 Eng. Agrônomo, Dr., Prof. Associado do Depto. de Agronomia, Universidade Estadual de Maringá, Campus Universitário, Av. Colombo, 5790, Bloco G56, Sala 35. Maringá, PR; Bolsista do CNPq; e-mail: albraccini@uol.com.br; e-mail: cascapim@uem.br

${ }_{4}$ Pesquisador do Centro Nacional de Pesquisa em Soja, CP. 231, CEP 96001-970, Londrina, PR, Brasil; e-mail: jmarcos@ @npso.embrapa.br

5 Eng. Agrônomo, Dr., Prof. Titular do Depto. de Agronomia, Universidade Estadual de Maringá, Maringá, PR; Bolsista do CNPq; e-mail: pedro.vidigal@ pesquisador.cnpq.br 


\section{INTRODUÇÃO}

Com uma composição química quase completa, a soja é um alimento essencialmente fornecedor de proteínas, ácidos graxos saturados e insaturados, algumas vitaminas, além de possuir compostos polifenólicos, como as isoflavonas.

As isoflavonas compreendem as agliconas - daidzeína, genisteína e gliciteína - e os glicosídeos respectivos daidzina, genistina e glicitina, bem como seus conjugados malonil e acetil (Carrão-Panizzi, 1996). O total de isoflavonas encontrado na soja distribui-se, basicamente, em isoflavonas glicosiladas e isoflavonas agliconas. Eldridge (1982) e Fukutake et al. (1996) afirmaram que genistina e daidzina constituem de 50 a $90 \%$ dos flavonóides encontrados da farinha de soja, enquanto as formas malonil genistina e malonil daidzina compreende cerca de $66 \%$ do total de isoflavonas nas sementes de soja maduras (Kudou et al., 1991).

Park et al. (2001), analisando diferentes cultivares de soja da mesma região brasileira, observaram grande variação na concentração de isoflavonas. Segundo CarrãoPanizzi et al. (1998) a concentração de isoflavonas em soja é geneticamente determinada e afetada por fatores ambientais, principalmente pela temperatura local.

Os níveis de isoflavonas na soja variam em mais que o triplo, dependendo da parte morfológica de onde é extraída (cotilédone, hipocótilo e casca), da variedade (fatores genéticos) e das condições ambientais (temperatura, umidade) de cultivo (Tsukamoto et al., 1995; Choi et al., 1996).

Nas células que compõem os tecidos das sementes, o efeito antioxidante, uma das principais propriedades das isoflavonas (Shahidi et al., 1992), poderia ser um importante mecanismo de garantia da qualidade das sementes, uma vez que a degradação da membrana celular pela ação de radicais livres é uma das mais discutidas e aceitas teorias de deterioração das sementes. Krzyzanowki et al. (2001) demonstraram que os teores de isoflavonas nas sementes estão relacionados com a melhor qualidade dessas.

Segundo Popinigis (1985), a qualidade fisiológica da semente é a sua capacidade de desempenhar funções vitais, caracterizadas pela sua germinação, seu vigor e sua longevidade. Além disso, está intimamente ligada a diversos fatores do ambiente, entre os quais a temperatura, a umidade (Tekrony et al., 1980; Vieira et al., 1982) e aos fatores genéticos.

A deterioração pode ser definida como um processo que envolve mudanças citológicas, bioquímicas e físicas que, eventualmente, causam a morte das sementes. Este processo de deterioração foi caracterizado por Delouche (1982) como inexorável e irreversível e tem sido ampla e profundamente estudado, mas o mecanismo exato ainda permanece inexplicado.

Vários fatores estão ligados à deterioração sendo eles: redução da atividade de enzimas; redução dos índices de respiração e biossíntese; e aumento da permeabilidade de membranas em nível celular e subcelular com conseqüente degradação das mitocôndrias (França Neto \& Henning, 1984).

Estudando a relação entre teor de isoflavonas, óleo e proteínas com a produção de sementes de soja Yin \& Vyn (2005), sugeriram que a alta produção de semente de soja pode ser acompanhada de alta concentração de isoflavonas, sem nenhum declínio substancial na concentração de óleo e proteínas.

Fatores genéticos também podem governar, a princípio, os teores de óleo e proteínas das sementes de soja, porém, estes são fortemente influenciados pelo ambiente, principalmente durante o período de enchimento das sementes.

Segundo Wilcox \& Cavines (1992) e Rao et al. (1993), as quantidades de óleo e proteínas também podem ser influenciadas pelo ambiente no qual o vegetal é cultivado. $O$ efeito da temperatura pode explicar as variações na concentração de proteínas, tanto entre locais, como entre anos em um mesmo local (Pípolo, 2002).

Singh et al. (1990) e Benzain \& Lane (1986) relataram efeito positivo entre temperatura e conteúdo de proteínas em grão-de-bico e trigo. Entretanto, Shafii et al. (1992) relataram relação inversa entre temperatura e óleo em sementes de canola.

Os objetivos do presente trabalho foram avaliar os componentes de produção, a qualidade fisiológica das sementes de soja produzidas em dois locais de semeadura e determinar os seus teores de óleo, proteínas e de isoflavonas, bem como correlacionar o conteúdo de 
isoflavonas com os componentes de rendimento, qualidade fisiológica, teores de óleo e proteínas das sementes de soja.

\section{MATERIAL E MÉTODOS}

Os experimentos foram realizados no ano agrícola de 2004/05, em área localizada na Fazenda Experimental de Iguatemi, localizada no município de Maringá - PR (Latitude

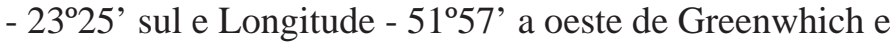
Altitude de 540m) e na Fazenda do Campus Regional de Umuarama - PR (Latitude - 234' sul e Longitude - 5314' a oeste de Greenwhich e Altitude de 403m), ambas, pertencentes à Universidade Estadual de Maringá. O clima predominante na região é do tipo Cfa, segundo classificação de Köppen (IAPAR, 1987).

Os experimentos foram instalados em dois solos de diferentes classificações. Em Maringá, em um solo classificado como LATOSSOLO VERMELHO Eutrófico de textura média; enquanto que em Umuarama, LATOSSOLO VERMELHO Distrófico de textura arenosa (EMBRAPA, 1999).

Os dados locais de precipitação pluviométrica, temperatura máxima e mínima diária e umidade relativa do ar, referentes ao período de duração dos ensaios estão apresentados na Figura 1 A e B.

As cultivares estudadas foram: BR 36, EMBRAPA 48, BRS 133, BRS 184, BRS 213, BRS 214.

$\mathrm{O}$ solo da área experimental foi analisado quanto às características químicas e a adubação de acordo com as recomendações técnicas para a cultura da soja (EMBRAPA Soja, 2002). A semeadura direta foi realizada na primeira quinzena de novembro em ambos os locais. As demais práticas culturais foram realizadas conforme preconizado pelo sistema de produção da região.

O delineamento experimental utilizado foi em blocos completos casualizados com quatro repetições. As parcelas experimentais foram constituídas de seis linhas de cinco metros de comprimento, espaçadas de $0,5 \mathrm{~m}$ entre si, com área total de $15 \mathrm{~m}^{2}$ em ambos locais.

A colheita foi realizada manualmente, cinco dias após o estádio de desenvolvimento $\mathrm{R}_{8}$, ou seja, quando $95 \%$ das vagens apresentavam a coloração típica de vagem madura (Fehr et al., 1971) eliminando-se as duas fileiras externas, bem como $0,5 \mathrm{~m}$ de cada extremidade das linhas centrais como bordaduras com uma área útil de $8 \mathrm{~m}^{2}$.

Após a colheita, as plantas da área útil de cada parcela, foram amarradas em feixes, os quais, foram identificados e levados para a debulha em máquina trilhadeira estacionária. As sementes provenientes da trilha mecânica foram limpas e classificadas com o auxílio de peneiras e acondicionadas em sacos de papel Kraft e posteriormente foram levadas a uma câmara fria, e acondicionadas a uma temperatura de aproximadamente $10^{\circ} \mathrm{C}$ e umidade relativa abaixo de $40 \%$, até o início das avaliações de laboratório.

As avaliações de laboratório foram realizadas no Laboratório de Tecnologia de Sementes do Núcleo de Pesquisas Aplicadas à Agricultura (NUPAGRI), pertencente ao Centro de Ciências Agrárias da Universidade Estadual de Maringá. As sementes foram avaliadas por meio dos diferentes testes de avaliação da qualidade fisiológica, bem como foram determinados os teores de óleo e proteínas o grau de umidade, o rendimento e a massa de mil sementes.

Produtividade de sementes: partindo-se do rendimento de sementes das parcelas, foram calculadas as produtividades em kg. ha-1 . Para o cálculo da produtividade, a umidade das sementes foi determinada por meio do método de estufa a $105^{\circ} \pm 3^{\circ} \mathrm{C}$ durante 24 horas (Brasil,1992) e corrigida para $13 \%$.

Massa de mil sementes: determinada por meio da pesagem de quatro subamostras de 100 sementes, para cada repetição de campo, com o auxílio de balança analítica ( $\pm 1 \mathrm{mg}$ ) e os dados multiplicados por 10 (Brasil, 1992).

Teste de germinação: conduzido com quatro subamostras de 50 sementes, para cada repetição de campo, colocadas para germinar entre três folhas de papel-toalha, umedecidas com água destilada, na proporção de três vezes a massa do papel seco embebido em água. Confeccionaram-se rolos, que foram levados ao germinador do tipo Mangelsdorf regulado para manter a temperatura constante de $25^{\circ} \pm 1^{\circ} \mathrm{C}$. A porcentagem de plântulas normais foi avaliada no oitavo dia, após o início do teste, segundo os critérios estabelecidos nas Regras para Análise de Sementes (Brasil, 1992).

Primeira contagem da germinação: efetuada em conjunto com o procedimento anterior, utilizando-se a mesma metodologia, considerando-se a somente as plântulas normais obtidas no quinto dia após o início do teste (Brasil, 1992). 


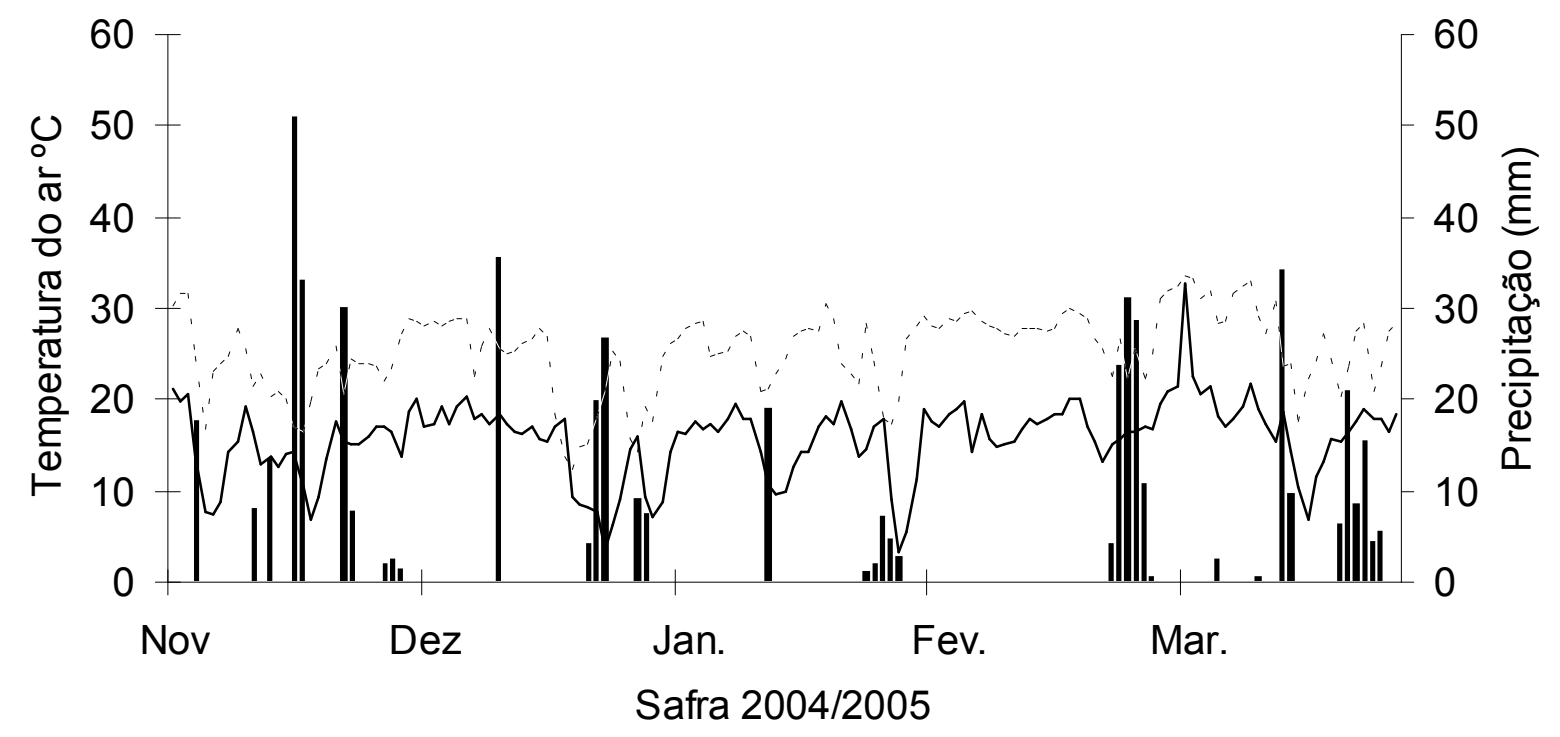

Precipitação … Máxima —Mínima

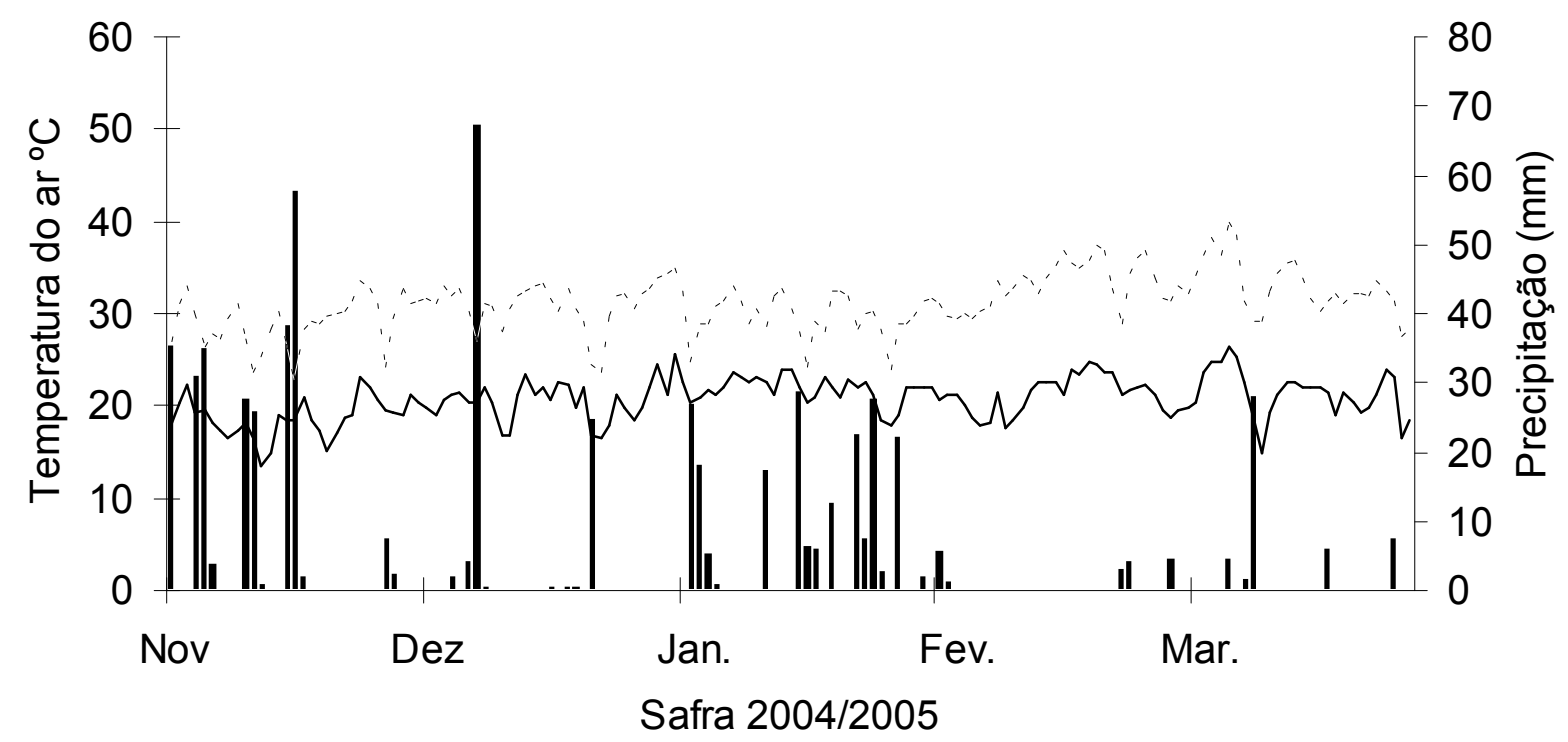

Precipitação … Máxima — Mínima

FIGURA 1. Precipitação pluvial e temperaturas máxima e mínima diárias observadas, durante a condução do experimento, em Maringá, Fazenda Experimental de Iguatemi (A) e Umuarama, Fazenda do Campus Regional (B). 
Teste de Tetrazólio: conduzido com quatro subamostras de 50 sementes por unidade experimental, que foram pré-condicionadas em papel-toalha umedecido com água destilada por um período de 16 horas, em germinador com temperatura ajustada para $25^{\circ} \mathrm{C}$. As sementes então foram transferidas para copos plásticos, com volume de $50 \mathrm{~mL}$, sendo totalmente submersas em solução de tetrazólio (2-3-5, trifenil cloreto de tetrazólio), à concentração de $0,075 \%$, e mantidas à temperatura de $40^{\circ} \mathrm{C}$ por aproximadamente 180 minutos no interior de uma câmara de germinação, na ausência de luz. Após o processo de coloração, as sementes foram lavadas com água corrente e mantidas submersas até o momento da avaliação. Posteriormente, as sementes foram avaliadas individualmente, seccionando-as longitudinalmente e simetricamente, com o auxílio de lâmina e classificadas de acordo com os critérios propostos por França Neto et al. (1998). A viabilidade foi representada pela proporção de sementes pertencentes às classes de 1 a 5; o nível de vigor, representado, pelas classes de 1 a 3 . O potencial de vigor e viabilidade, foram expressos em percentagem (França Neto et al., 1999).

Teor de proteínas: determinada pelo método de Kjeldahl (Nitrogênio total), conforme recomendação da Association of Official Analytical Chemists (A.O.A.C., 1975), com modificações. Sementes provenientes de cada repetição de campo foram moídas durante 60 segundos em um moinho de faca a 17000r.p.m.. Posteriormente, foram analisadas quatro subamostras de $0,2 \mathrm{~g}$ da farinha de soja moída, a qual foi condicionada em tubos de ensaio, junto com $2 \mathrm{~g}$ de uma mistura catalítica (sulfato de cobre e selênio em pó) e $5 \mathrm{~mL}$ de ácido sulfúrico concentrado. Estes tubos foram levados para aquecimento em um bloco digestor, para a fase de digestão da matéria orgânica. $\mathrm{O}$ aquecimento foi gradual até a temperatura de $350^{\circ} \mathrm{C}$, permanecendo nesta temperatura por mais 2,5 horas. Após a digestão, iniciou-se a fase de destilação da amônia liberada, pela a reação com hidróxido de sódio (50\%), a qual foi recolhida em solução de acido bórico a 4\%. A titulação foi realizada em solução padrão de ácido clorídrico (1 N), sendo recuperado 99,7\% de nitrogênio. Para a determinação de proteínas total, multiplicou-se o conteúdo de nitrogênio pelo fator 6,25 , com base na matéria seca.
Teor de óleo: na determinação de lipídio total (óleo), utilizou-se o aparelho extrator de Soxhlet (TE 044) e éter de petróleo como solvente, segundo procedimento descrito nas Normas Analíticas do Instituto Adolfo Lutz (I.A.L., 1985), com refluxo de 6 horas. Avaliaram-se quatro subamostras de $2 \mathrm{~g}$ de farinha de soja, provenientes de amostras das sementes de cada repetição de campo. Os resultados foram expressos em porcentagem de óleo extraído.

O total de isoflavonas das sementes foram determinados na Embrapa Soja (Centro Nacional de Pesquisa em Soja), em Londrina - PR.

Teor de isoflavonas: as sementes de cada cultivar de soja proveniente dos diferentes ambientes foram moídas, com o auxílio de um moinho de facas, durante 60 segundos, a uma rotação de 17000 r.p.m. Posteriormente, $15 \mathrm{~g}$ dessa farinha foi misturada com $50 \mathrm{~mL}$ de hexano permanecendo sob agitação constante, durante 24 horas à temperatura ambiente, e então filtrada, obtendo-se farinha desengordurada de soja (FDS).

Para a extração de isoflavonas, 100mg desta FDS foi acondicionada em tubos de ensaio (10mL) com tampa e recebeu $4 \mathrm{~mL}$ de solução de etanol $70 \%$ mais $0,1 \%$ de ácido acético. Os tubos de ensaio permaneceram por uma hora a temperatura ambiente, sendo agitados vigorosamente a cada 15 minutos. Posteriormente, $2 \mathrm{~mL}$ deste extrato foram centrifugados durante 4 minutos a 15000r.p.m.. O sobrenadante obtido foi transferido para os tubos de auto injetar do cromatógrafo. Alíquotas de 40ì do sobrenadante foram utilizadas para injeções diretas no aparelho. Cada amostra teve duas repetições de análise por cromatografia líquida de alta eficiência (HPLC), de acordo com o procedimento realizado por Carrão-Panizzi et al. (2002).

A separação e a quantificação de isoflavonas foram realizadas de acordo coma metodologia preconizada por Berhow (2002) em cromatógrafo líquido da marca Waters, modelo 2690, com injetor automático de amostras. Utilizouse uma coluna de fase reversa do tipo ODS C18 (YMC Pack ODS-AM Columm) com 250mm de comprimento $\mathrm{x}$ $0,4 \mathrm{~mm}$ de diâmetro interno e partículas de 5ìm. Para separação das isoflavonas, adotou-se o sistema de gradiente linear binário, tendo-se como fases móveis: metanol com $0,025 \%$ de ácido trifluoroacético (TFA) como solvente A e água destilada deionizada ultrapura contendo $0,025 \%$ de 
TFA como solvente B. O gradiente inicial foi de $20 \%$ para o solvente $\mathrm{A}$, que aos 40 minutos atingiu a concentração de $100 \%$ para em seguida, retornar a $20 \%$ aos 41 minutos e permanecendo assim até os 60 minutos que foi o tempo total de corrida para cada amostra. A vazão da fase móvel foi de $1 \mathrm{~mL}$. $\mathrm{min}^{-1} \mathrm{e}$ a temperatura durante a corrida, $25^{\circ} \mathrm{C}$. A detecção das isoflavonas foi realizada utilizando o detector de arranjo de foto diodo da marca Waters, modelo 996, ajustado para o comprimento de onda igual à $260 \mathrm{~nm}$. Para a detecção das isoflavonas, foram utilizados padrões de daidzina, daidzeína, genistina e genisteína, da marca Sigma, solubilizados em metanol (grau HPLC), nas seguintes concentrações: $0,00625 \mathrm{mg} . \mathrm{mL}^{-1} ; 0,0125 \mathrm{mg} . \mathrm{mL}^{-1} ; 0,0250$ mg. $\mathrm{mL}^{-1} ; 0,05 \mathrm{mg}$. mL $\mathrm{m}^{-1}$ e $0,1000 \mathrm{mg}$. $\mathrm{mL}^{-1}$. Para a quantificação das formas malonil foram utilizados os padrões externos como referência, bem como o coeficiente de extinção molar de cada uma delas. O teor de isoflavonas foi calculado em miligrama por $100 \mathrm{~g}$ de farinha.

Análise estatística: Os dados obtidos em todos os testes para cada experimento, isoladamente, foram submetidos à análise de variância. Em seguida, verificouse a semelhança dos quadrados médios do erro pelo Teste de Hartley (Ramalho, 2000) e também a razão entre o maior e o menor quadrado médio residual (Banzatto \& Kronka, 1992). A análise conjunta dos dados foi realizada para locais, uma vez que existiu homogeneidade das variâncias e a razão entre o maior e o menor quadrado médio residual não foi superior a sete. $\mathrm{Na}$ análise conjunta, os efeitos de cultivar e locais foram considerados fixos e na presença de interação significativa entre cultivares e locais procederam-se os desdobramentos necessários. Os efeitos das cultivares foram comparados pelo teste de agrupamento de médias de Scott-Knott (Scott \& Knott, 1974), em nível de 5\% de probabilidade, enquanto que a comparação entre os locais foi realizada pelo teste F. Posteriormente, calcularam-se os coeficientes de correlação simples de Pearson (r) para todas as combinações entre os testes de avaliação da qualidade das sementes, componentes da produção e teores de óleo e proteínas, em relação ao teor de isoflavonas, para cada ambiente, em que a significância dos valores de $r$ foi determinada pelo teste $\mathrm{t}$, a $5 \%$ de probabilidade.

\section{RESULTADOS E DISCUSSÃO}

O resultado da análise conjunta dos dados revelou que a interação entre cultivar $v s$ local foi significativa $(\mathrm{p}<0,05)$ para as variáveis rendimento, germinação, primeira contagem de germinação, tetrazólio (vigor), tetrazólio (viabilidade), teor de proteínas, óleo e isoflavonas, indicando que ocorreram diferentes respostas das cultivares em relação aos locais de semeadura.

Os dados climáticos de temperatura mínima, máxima e precipitação pluviométrica diária, coletados durante a condução dos ensaios, nos dois locais de semeadura, encontram-se ilustrados na Figura 1. Para Maringá (Figura $1 \mathrm{~A}$ ), a temperatura média do ar oscilou entre $15,8^{\circ} \mathrm{C}$ e $25,4^{\circ} \mathrm{C}$ nos meses de novembro a março com precipitação média de 90,4mm. Em Umuarama (Figura 1 B), a temperatura média do ar oscilou entre $20,3^{\circ} \mathrm{C}$ e $31,0^{\circ} \mathrm{C}$ com precipitação média mensal de 127,9mm (Figura $1 \mathrm{~B}$ ).

Os resultados do rendimento das sementes de todas as cultivares de soja, em cada local, apresentaram diferenças significativas sendo as cultivares BR 36, EMBRAPA 48 e BRS 133 as mais produtivas em Maringá e EMBRAPA 48, BRS 133 e BRS 184, as mais produtivas em Umuarama (Tabela 1). Comparando o desempenho de cada cultivar entre os dois locais, observa-se que todos as cultivares mantiveram o mesmo rendimento de sementes, independentemente do ambiente de semeadura. A cultivar BRS 184, quando produzida em Maringá, apresentou produtividade de $40,71 \%$ superior à Umuarama.

O rendimento de sementes foi relativamente baixo para todos os materiais testados e em ambos os locais, devido às condições climáticas registradas no período de condução do experimento, principalmente em relação à deficiência hídrica. Nas Figuras 1 A e B, observa-se que os meses de dezembro e janeiro foram os que apresentaram menor precipitação, principalmente o mês de janeiro para Maringá, coincidindo com a fase reprodutiva da cultura.

O efeito da deficiência hídrica na produção depende da época de ocorrência e de sua severidade. Para a cultura da soja, a fase reprodutiva é a mais crítica. No florescimento, causa o abortamento das flores e impede a antese, enquanto no enchimento dos grãos, afeta a massa das sementes e, 
conseqüentemente, a produção (Fageria, 1989). A inibição da expansão foliar é uma das primeiras respostas ao estresse hídrico, com conseqüente queda da eficiência do processo fotossintético (Taiz \& Zeiger, 2004). Os mesmos autores comentam ainda os efeitos da associação entre estresse por calor e déficit hídrico, onde a restrição da transpiração superaquece a folha e o estresse pelo calor inibe a fotossíntese e prejudica a função de membranas e a estabilidade protéica.

A quantidade de água armazenada no solo disponível às plantas varia com a sua textura e características físicas. Solos argilosos retêm água em maior quantidade que os solos de textura arenosa, devido à maior área superficial e a poros menores entre partículas.

O estresse hídrico sofrido pela cultura da soja durante o período de enchimento de grãos pode afetar a produção, principalmente em relação à massa de mil sementes (Tabela $1)$.

Para a massa de mil sementes foram observadas diferenças significativas entre as cultivares, para cada local (Tabela 1), evidenciando a cultivar BR $36 \mathrm{com}$ os valores mais altos tanto em Maringá quanto em Umuarama. Porém, quando comparou-se a massa de mil sementes de cada cultivar, nos diferentes locais de semeadura, não houve diferença significativa ( $p>0,05)$, ou seja, a massa de mil sementes das seis cultivares foi semelhante tanto para Umuarama quanto para Maringá.

$\mathrm{Na}$ análise dos resultados obtidos na avaliação do rendimento com a massa de mil sementes, observa-se que não houve relação direta entre esses componentes de produção em relação às cultivares. Apesar de terem apresentado os menores valores para a massa de mil sementes, as cultivares BRS 133 e EMBRAPA 48 apresentaram as maiores produtividades em Maringá. Já a cultivar BR 36 apresentou maior massa de mil sementes, sem alteração significativa no rendimento de sementes. Resultados semelhantes foram obtidos em Umuarama para as cultivares BRS 133 e EMBRAPA 48 (Tabela 1). Motta et al. (2000) encontraram valores inversos a este, ou seja, apesar de determinada cultivar ter apresentado maior valor para a massa de mil sementes, não foi a mais produtiva.

Os resultados do teste de germinação e primeira contagem de germinação, na comparação das cultivares e locais de semeadura encontra-se na Tabela 2. Comparandose a porcentagem de plântulas normais, observa-se que, dependendo do local de cultivo, houve uma resposta diferenciada para cada cultivar. Quando cultivadas em Maringá, não houve diferença significativa $(\mathrm{p}<0,05)$ quanto a porcentagem de plântulas normais obtidas na primeira contagem de germinação, apresentando o mesmo vigor entre as cultivares. Entretanto, as sementes das cultivares BR 36 e BRS 214 produzidas em Umuarama foram as que apresentaram menor vigor no referido teste. Comparando o vigor das sementes de cada cultivar em relação ao local de semeadura, verifica-se que houve diferença significativa entre Maringá e Umuarama para as cultivares BR 36, BRS 184 BRS 213 e BRS 214. Os mesmos resultados foram obtidos na contagem final do teste de germinação das sementes das diferentes cultivares analisadas (Tabela 2).

As sementes de todas as cultivares semeadas em Maringá apresentaram germinação superior a $80 \%$, enquanto que, para Umuarama, somente as cultivares EMBRAPA 48 e BRS 133 apresentaram os mesmos resultados, atingindo o padrão mínimo comercial para o Estado do Paraná (Paraná, 1986).

A avaliação das sementes pelo teste de tetrazólio, a fim de determinar o potencial de vigor e viabilidade das sementes das diferentes cultivares de soja semeadas em Maringá e Umuarama, está apresentada na Tabela 3. Nenhuma diferença significativa foi observada entre o vigor das sementes das seis cultivares de soja produzidas em Umuarama e Maringá.

Verificou-se, porém que as sementes das cultivares BR 36, BRS 184 e BRS 213 apresentaram maior percentual de vigor quando produzidas em Maringá. As sementes produzidas em Umuarama apresentaram vigor baixo a muito baixo, ao passo que as produzidas em Maringá, vigor médio a baixo.

A viabilidade das sementes (Tabela 3) não revelou diferenças significativa $(p>0,05)$ entre as cultivares para cada local; contudo, quando comparam-se os locais para cada cultivar, houve diferentes respostas para as cultivares BR 36, BRS 184 e BRS 213. Os valores do potencial de vigor e viabilidade no teste de tetrazólio, observados na Tabela 3 estão de acordo com os valores observados na Tabela 4 para o teste de germinação das sementes. 
TABELA 1. Produtividade e massa de mil sementes de seis cultivares de soja produzidas em Maringá e Umuarama - PR, no ano agrícola de 2004/2005.

\begin{tabular}{|c|c|c|c|c|c|c|}
\hline \multirow[t]{2}{*}{ Local $^{2}$} & \multicolumn{6}{|c|}{ Cultivares $^{1}$} \\
\hline & BR 36 & EMBRAPA 48 & BRS 133 & BRS 184 & BRS 213 & BRS 214 \\
\hline & \multicolumn{6}{|c|}{ Produtividade $\left(\mathrm{kg} \mathrm{ha}^{-1}\right)$} \\
\hline Maringá & 3168,99 Аа & $3188,00 \mathrm{Aa}$ & 3397,79 Аа & $3283,27 \mathrm{Aa}$ & $2556,43 \mathrm{Ba}$ & $2530,43 \mathrm{Ba}$ \\
\hline Umuarama & $2829,20 \mathrm{Ba}$ & $3382,57 \mathrm{Aa}$ & $3053,79 \mathrm{Aa}$ & $2333,32 \mathrm{Bb}$ & $2355,47 \mathrm{Ba}$ & $2614,22 \mathrm{Ba}$ \\
\hline Média & 2999,09 & 3285,29 & 3225,67 & 2808,30 & 2455,95 & 2572,33 \\
\hline \multirow[t]{2}{*}{ C.V. $(\%)$} & 10,11 & & & & & \\
\hline & \multicolumn{6}{|c|}{ Massa de mil sementes (g) } \\
\hline Maringá & $186,87 \mathrm{Aa}$ & $155,28 \mathrm{Ca}$ & $130,62 \mathrm{Da}$ & $154,25 \mathrm{Ca}$ & $168,90 \mathrm{Ba}$ & $164,34 \mathrm{Ba}$ \\
\hline Umuarama & $189,12 \mathrm{Aa}$ & $158,78 \mathrm{Ca}$ & $134,37 \mathrm{Da}$ & $157,75 \mathrm{Ca}$ & $172,15 \mathrm{Ba}$ & $167,59 \mathrm{Ba}$ \\
\hline Média & 187,99 & 157,03 & 144,31 & 144,19 & 170,53 & 165,97 \\
\hline C.V. $(\%)$ & 6,03 & & & & & \\
\hline
\end{tabular}

TABELA 2. Plântulas normais fortes obtidas na primeira contagem do teste de germinação e plântulas normais fortes e fracas obtidas na contagem final do teste de germinação das sementes de seis cultivares de soja produzidas em Maringá e Umuarama - PR, no ano agrícola de 2004/2005.

\begin{tabular}{lcccccc}
\hline \multirow{2}{*}{ Local $^{2}$} & \multicolumn{7}{c}{ Cultivares $^{1}$} \\
\cline { 2 - 7 } & BR 36 & EMBRAPA 48 & BRS 133 & BRS 184 & BRS 213 & BRS 214 \\
\hline Maringá & $86,25 \mathrm{Aa}$ & $77,00 \mathrm{Aa}$ & $90,35 \mathrm{Aa}$ & $90,62 \mathrm{Aa}$ & $87,37 \mathrm{Aa}$ & $77,62 \mathrm{Aa}$ \\
Umuarama & $41,87 \mathrm{Bb}$ & $79,00 \mathrm{Aa}$ & $77,00 \mathrm{Aa}$ & $67,25 \mathrm{Ab}$ & $73,50 \mathrm{Ab}$ & $55,37 \mathrm{Bb}$ \\
\hline Média & 64,06 & 78,00 & 83,67 & 78,93 & 80,43 & 66,49 \\
\hline C.V. (\%) & 13,17 & \multicolumn{7}{c}{ Primeira contagem (\%) } \\
\hline \multicolumn{7}{c}{ Contagem final (\%) } \\
\hline Maringá & $87,12 \mathrm{Aa}$ & $84,50 \mathrm{Aa}$ & $92,62 \mathrm{Aa}$ & $92,87 \mathrm{Aa}$ & $91,37 \mathrm{Aa}$ & $84,12 \mathrm{Aa}$ \\
Umuarama & $46,00 \mathrm{Bb}$ & $81,50 \mathrm{Aa}$ & $81,87 \mathrm{Aa}$ & $72,87 \mathrm{Ab}$ & $76,50 \mathrm{Ab}$ & $58,12 \mathrm{Bb}$ \\
\hline Média & 66,56 & 83,00 & 87,24 & 82,87 & 83,93 & 71,12 \\
\hline C.V. (\%) & 11,16 & \multicolumn{5}{c}{} \\
\hline
\end{tabular}

${ }^{1}$ Médias seguidas de mesma letra maiúscula na linha pertencem a um mesmo grupo, de acordo com o critério de agrupamento de Scott-Knott (1974), a 5\% de probabilidade.

${ }^{2}$ Médias seguidas de mesma letra minúscula, em cada coluna, não diferem entre si pelo teste $\mathrm{F}$, a $5 \%$ de probabilidade. 
A região de Umuarama é considerada pouco favorável para a produção de sementes, enquanto que a região de Maringá é medianamente favorável, por apresentarem durante o período de maturação das sementes, temperaturas médias superiores a $24^{\circ} \mathrm{C}$ e entre $22^{\circ} \mathrm{C}$ e $24^{\circ} \mathrm{C}$, respectivamente (Costa et al., 1992). Os ambientes mais favoráveis à produção de sementes de soja de melhor qualidade fisiológica são aqueles com temperatura média inferior a $22^{\circ} \mathrm{C}$.

Trabalhos de Tekrony et al. (1980) e Vieira et al. (1982) indicaram o efeito marcante da temperatura como parâmetro determinante da baixa qualidade de sementes de soja. Da mesma forma, estudos conduzidos por Keigley \& Mullen (1986) indicam redução da germinação e do vigor para sementes de soja produzidas em períodos de deficiência hídrica, o que ocorreu em vários períodos durante os estádios reprodutivos da cultura nesse experimento.

Assim como o déficit hídrico, o excesso de chuva pode prejudicar a qualidade da semente. Neste contexto, Vieira et al. (1982) constataram que condições quentes e úmidas, com precipitações pluviométricas em demasia na maturação, poderão comprometer severamente a germinação e o vigor das sementes.

$\mathrm{Na}$ Tabela 4, podem ser observados os resultados referentes aos teores de óleo e proteínas nas sementes. O teor de óleo nas sementes das cultivares BR 36, EMBRAPA 48, BRS 133 produzidas em Maringá, foi maior em comparação com as demais cultivares. Em contrapartida, as cultivares BRS 133, BRS 184 e BRS 214 foram as que apresentaram maior teor de óleo, quando produzidas em Umuarama. Todas as cultivares que foram semeadas em Umuarama apresentaram menor teor de óleo, quando comparadas com a semeadura realizada em Maringá.

Altas temperaturas durante o desenvolvimento das sementes estão associadas com a redução no teor de óleo total, porém, em condições campo, este efeito é variável de acordo com outros fatores ambientais, tais como o estresse hídrico, que influencia a produção de óleo através de seus efeitos sobre o crescimento e o desenvolvimento da semente (Harris et al., 1978).

O teor de proteínas não foi alterado, tanto para as cultivares, quanto para os locais de semeadura (Tabela 4).

Resultados discutidos por Sediyama et al. (1993), permitem afirmar que o conteúdo de proteína na semente de soja é inversamente associado ao teor de óleo. Entretanto, a temperatura não parece estar fortemente associada com o conteúdo de proteína e tem pouco efeito na quantidade encontrada na semente.

Apesar do controle genético, a concentração de proteínas da soja parece ser influenciada pela disponibilidade de $\mathrm{N}$. Como o $\mathrm{N}$ da fixação simbiótica vai para a formação da semente, a maximização do processo de fixação pode contribuir com uma maior concentração de $\mathrm{N}$ e, conseqüentemente, de proteínas nos grãos de soja.

Em princípio, os teores de óleo e proteínas das sementes de soja são determinados geneticamente, porém, fortemente influenciados pelo ambiente, principalmente durante o período de enchimento dos grãos.

Rangel et al. (2004) afirmaram que, assim como com o estresse hídrico, o efeito da temperatura pode explicar as variações na concentração de proteínas, tanto entre locais como entre anos, em um mesmo local. Em relação aos valores de temperatura média observada em Maringá e Umuarama, no período de condução desse experimento, Pípolo (2002) observou tendência das sementes coletadas nos locais com temperaturas médias mais amenas $\left(21^{\circ}\right.$ a $23^{\circ} \mathrm{C}$ ) e com maior altitude (maior que $650 \mathrm{~m}$ ) apresentarem maior concentração de proteínas do que aquelas coletadas nos locais com temperaturas mais altas $\left(23^{\circ}\right.$ a $\left.27^{\circ} \mathrm{C}\right)$.

O total de isoflavonas e cada uma de suas formas encontradas nas sementes das seis cultivares de soja produzidas em Maringá e Umuarama estão apresentados na Tabela 5. Tanto em Maringá como em Umuarama, o teor de isoflavonas totais das sementes produzidas foi maior para as cultivares EMBRAPA 48 e BRS 133 e menor para a cultivar BR 36. Não houve diferença entre os locais para essa variável, exceto para a cultivar BRS 133.

As formas glicosil e malonil isoflavonas apresentaram respostas diferenciadas das cultivares para com os diferentes locais e de cada local para com as diferentes cultivares. O conteúdo de daidzina das cultivares BRS 133 e BRS 184 diferiu significativamente $(\mathrm{p}<0,05)$ entre as duas localidades, sendo que os menores valores foram verificados em Maringá. As cultivares que apresentaram os menores valores de daidzina foram BR 36 e BRS 184, tanto em Maringá quanto em Umuarama.

O conteúdo de glicitina não apresentou diferença significativa $(p>0,05)$ entre os diferentes ambientes. No 
TABELA 3. Potencial de vigor (1 - 3) e de viabilidade (1 - 5) obtidos no teste de tetrazólio realizado nas sementes de seis cultivares de soja produzidas em Maringá e Umuarama - PR, no ano agrícola de 2004/2005.

\begin{tabular}{|c|c|c|c|c|c|c|}
\hline \multirow{2}{*}{ Local $^{2}$} & \multicolumn{6}{|c|}{ Cultivares $^{1}$} \\
\hline & BR 36 & EMBRAPA 48 & BRS 133 & BRS 184 & BRS 213 & BRS 214 \\
\hline & \multicolumn{6}{|c|}{ Vigor (\%) } \\
\hline Maringá & $71,75 \mathrm{Aa}$ & $71,25 \mathrm{Aa}$ & $65,50 \mathrm{Aa}$ & $68,50 \mathrm{Aa}$ & $65,25 \mathrm{Aa}$ & $58,00 \mathrm{Aa}$ \\
\hline Umuarama & $47,50 \mathrm{Ab}$ & $58,75 \mathrm{Aa}$ & $58,50 \mathrm{Aa}$ & $55,00 \mathrm{Ab}$ & $47,25 \mathrm{Ab}$ & $50,00 \mathrm{Aa}$ \\
\hline Média & 59,62 & 65,00 & 62,50 & 61,75 & 56,25 & 54,00 \\
\hline \multirow[t]{2}{*}{ C.V. $(\%)$} & 9,79 & & & & & \\
\hline & \multicolumn{6}{|c|}{ Viabilidade (\%) } \\
\hline Maringá & $92,25 \mathrm{Aa}$ & $91,00 \mathrm{Aa}$ & $86,50 \mathrm{Aa}$ & $91,75 \mathrm{Aa}$ & $91,50 \mathrm{Aa}$ & $88,75 \mathrm{Aa}$ \\
\hline Umuarama & $73,75 \mathrm{Ab}$ & $83,00 \mathrm{Aa}$ & $80,75 \mathrm{Aa}$ & $74,75 \mathrm{Ab}$ & $74,25 \mathrm{Ab}$ & $76,00 \mathrm{Aa}$ \\
\hline Média & 83,00 & 87,00 & 83,62 & 83,25 & 82,87 & 82,37 \\
\hline C.V. (\%) & 10,07 & & & & & \\
\hline
\end{tabular}

${ }^{2}$ Médias seguidas de mesma letra minúscula, em cada coluna, não diferem entre si pelo teste F, a 5\% de probabilidade.

TABELA 4. Teores de óleo e proteínas nas sementes de seis cultivares de soja cultivadas em Maringá e Umuarama - PR, no ano agrícola de 2004/2005.

\begin{tabular}{|c|c|c|c|c|c|c|}
\hline \multirow{2}{*}{ Local $^{2}$} & \multicolumn{6}{|c|}{ Cultivares $^{1}$} \\
\hline & BR 36 & EMBRAPA 48 & BRS 133 & BRS 184 & BRS 213 & BRS 214 \\
\hline & \multicolumn{6}{|c|}{ Óleo (\%) } \\
\hline Maringá & $21,71 \mathrm{Aa}$ & $21,52 \mathrm{Aa}$ & $21,30 \mathrm{Aa}$ & $19,49 \mathrm{Ba}$ & $19,49 \mathrm{Ba}$ & $19,35 \mathrm{Ba}$ \\
\hline Umuarama & $16,42 \mathrm{Bb}$ & $16,08 \mathrm{Bb}$ & $18,01 \mathrm{Ab}$ & $17,41 \mathrm{Ab}$ & $16,54 \mathrm{Bb}$ & $17,22 \mathrm{Ab}$ \\
\hline Média & 19,06 & 18,80 & 19,65 & 18,45 & 18,01 & 18,28 \\
\hline \multirow[t]{2}{*}{ C.V. $(\%)$} & 4,37 & & & & & \\
\hline & \multicolumn{6}{|c|}{ Proteínas (\%) } \\
\hline Maringá & $31,09 \mathrm{Aa}$ & $30,68 \mathrm{Aa}$ & 29,96 Аa & $31,04 \mathrm{Aa}$ & $31,70 \mathrm{Aa}$ & $33,01 \mathrm{Aa}$ \\
\hline Umuarama & $34,85 \mathrm{Aa}$ & $31,85 \mathrm{Aa}$ & $31,40 \mathrm{Aa}$ & $32,67 \mathrm{Aa}$ & $34,57 \mathrm{Aa}$ & $30,70 \mathrm{Aa}$ \\
\hline Média & 32,97 & 31,26 & 30,68 & 31,85 & 33,13 & 31,85 \\
\hline C.V. (\%) & 8,40 & & & & & \\
\hline
\end{tabular}


entanto, quando comparam-se as cultivares para cada local, não houve diferença significativa $(p>0,05)$ apenas para Umuarama. Em Maringá, os menores conteúdos desta isoflavona foram observados para a cultivar BR 36 .

$O$ conteúdo de genistina apresentou diferença significativa $(p<0,05)$ entre as diferentes localidades, sendo que os menores valores foram verificados em Maringá, para as cultivares EMBRAPA 48 e BRS 133. Para Maringá, as cultivares BR 36 e BRS 184 foram as que apresentaram menores valores no conteúdo de genistina. Em Umuarama, a cultivar EMBRAPA 48 foi a que apresentou maior conteúdo e a BR 36, o menor (Tabela 5).

O conteúdo de malonil daidzina das cultivares EMBRAPA 48 e BRS 133 diferiu significativamente $(p<0,05)$ entre as duas localidades. Para a cultivar EMBRAPA 48, o menor valor foi verificado em Maringá, enquanto que, para a cultivar BR 133, em Umuarama. A cultivar BR 36 foi aquela que apresentou menor valor de malonil daidzina, tanto em Maringá como em Umuarama (Tabela 5).

O conteúdo de malonil glicitina apresentou diferença significativa $(p<0,05)$ entre as diferentes localidades para as cultivares EMBRAPA 48, BRS 184 e BRS 214, sendo que todas apresentaram maiores conteúdos em Maringá. Quando se comparou as cultivares em cada local, observouse que, em Maringá, o menor conteúdo foi verificado para a cultivar BR 36 ao passo que, em Umuarama, o maior conteúdo foi verificado nas cultivares EMBRAPA 48 e BRS 133 (Tabela 6).

O conteúdo de malonil genistina apresentou diferença significativa $(\mathrm{p}<0,05)$ entre as diferentes localidades para as cultivares BR 36 (menor conteúdo em Umuarama), EMBRAPA 48 e BRS 133 (menor conteúdo em Maringá). A cultivar BR 36 apresentou o menor valor desta isoflavona, quando comparado com as demais cultivares, tanto em Maringá quanto em Umuarama (Tabela 6).

Diferenças no total de isoflavonas para cada cultivar podem estar relacionadas à sua característica genética. Por outro lado, algumas cultivares podem ser relativamente estáveis quanto à resposta aos teores de isoflavonas, e pequenas variações podem ocorrer por influência do local, da época de semeadura (Carrão-Panizzi, 1996), confirmando os resultados obtidos nesse experimento (Tabela 6).
Carrão-Panizzi \& Kitamura (1995) constataram que a cultivar BR 36 possui teor reduzido de isoflavonas e relataram que há variabilidade no teor de isoflavonas entre as cultivares brasileiras. O efeito do genótipo já foi demonstrado no trabalho conduzido por Wang \& Murphy (1994). O teor dos compostos nas cultivares muda em função do local de semeadura, de acordo com a Tabela 5, porém, a característica do teor elevado ou reduzido persiste da mesma forma como observado por Carrão-Panizzi (1996).

A variação no teor de isoflavonas na soja é determinada geneticamente, porém, fortemente influenciada pelo ambiente. Temperaturas mais frias durante o período de enchimento de vagens aumentaram as concentrações de isoflavonas (Carrão-Panizzi et al., 2003).

O teor total de isoflavonas obtido nesse trabalho está em desacordo com os trabalhos de Kitamura et al. (1991), Tsukamoto et al. (1995) e Carrão-Panizzi (1996), os quais relataram que temperaturas mais elevadas no período de desenvolvimento dos grãos diminuíram o teor das isoflavonas, sugerindo o efeito do ambiente sobre o conteúdo de isoflavonas.

A variabilidade e as mudanças globais no clima e a composição atmosférica podem interferir no comportamento da cultura da soja, aumentando ou diminuindo a quantidade e qualidade das sementes colhidas, influenciando nos principais componentes da semente, óleo, proteína e carboidratos (Bordignon et al., 2006), assim como no total de isoflavonas (Caldwell et al., 2005).

Nas Tabelas 6 e 7, estão apresentados os valores de correlação entre os componentes de produção, testes utilizados para determinar a qualidade fisiológica das sementes e os teores de óleo e proteínas nos dois ambientes (Maringá e Umuarama), em relação ao teor de isoflavonas totais e suas diferentes formas. Esses resultados revelaram que a massa de mil sementes possui correlação negativa com o teor de isoflavonas totais e com as formas de isoflavonas em ambos locais de semeadura, assim como o teor de óleo.

Segundo Daydé \& Lacombe (2000), o conteúdo de isoflavonas possui correlação positiva com a massa de mil sementes, o que contraria os resultados deste trabalho.

Os resultados da Tabela 6 indicam que não houve correlação significativa $(\mathrm{p}>0,05)$ para o teor de proteínas das sementes com o conteúdo de isoflavonas em Maringá, 
TABELA 5. Conteúdo de isoflavonas nas sementes de seis cultivares de soja cultivadas em Maringá e Umuarama - PR, no ano agrícola de 2004/2005.

\begin{tabular}{|c|c|c|c|c|c|c|}
\hline \multirow{2}{*}{ Local $^{2}$} & \multicolumn{6}{|c|}{ Cultivares $^{1}$} \\
\hline & BR 36 & EMBRAPA 48 & BRS 133 & BRS 184 & BRS 213 & BRS 214 \\
\hline & \multicolumn{6}{|c|}{ Total de isoflavonas (mg. $100 \mathrm{~g}^{-1}$ de farinha) } \\
\hline Maringá & $87,30 \mathrm{Ca}$ & $185,13 \mathrm{Aa}$ & $168,20 \mathrm{Ab}$ & $139,97 \mathrm{Ba}$ & $147,95 \mathrm{Ba}$ & $174,30 \mathrm{Ba}$ \\
\hline Umuarama & $89,24 \mathrm{Da}$ & $178,62 \mathrm{Aa}$ & $202,24 \mathrm{Aa}$ & $132,41 \mathrm{Ca}$ & $148,01 \mathrm{Ba}$ & $158,00 \mathrm{Ba}$ \\
\hline Média & 88,27 & 181,87 & 185,22 & 136,19 & 147,98 & 166,15 \\
\hline \multirow[t]{2}{*}{ C.V. $(\%)$} & 10,40 & & & & & \\
\hline & \multicolumn{6}{|c|}{ Daidzina (mg. $100 \mathrm{~g}^{-1}$ de farinha) } \\
\hline Maringá & $9,37 \mathrm{Ca}$ & $22,22 \mathrm{Aa}$ & $17,66 \mathrm{Bb}$ & $10,70 \mathrm{Cb}$ & $14,74 \mathrm{Ba}$ & $16,69 \mathrm{Ba}$ \\
\hline Umuarama & $13,38 \mathrm{Ba}$ & $21,39 \mathrm{Aa}$ & $23,47 \mathrm{Aa}$ & $16,41 \mathrm{Ba}$ & $19,23 \mathrm{Aa}$ & $18,84 \mathrm{Aa}$ \\
\hline Média & 12,89 & 21,80 & 20,56 & 13,55 & 16,98 & 17,76 \\
\hline \multirow[t]{2}{*}{ C.V. $(\%)$} & 18,66 & & & & & \\
\hline & \multicolumn{6}{|c|}{ Glicitina (mg. $100 \mathrm{~g}^{-1}$ de farinha) } \\
\hline Maringá & $2,95 \mathrm{Ba}$ & $9,73 \mathrm{Aa}$ & $8,73 \mathrm{Aa}$ & 6,33 Аa & 6,52 Aa & 7,31 Aa \\
\hline Umuarama & $6,07 \mathrm{Aa}$ & $8,70 \mathrm{Aa}$ & $9,75 \mathrm{Aa}$ & $8,14 \mathrm{Aa}$ & $9,43 \mathrm{Aa}$ & 6,86 Aa \\
\hline Média & 4,51 & 9,21 & 9,24 & 7,23 & 7,97 & 7,08 \\
\hline C.V. (\%) & 30,80 & & & & & \\
\hline
\end{tabular}

${ }^{1}$ Médias seguidas de mesma letra maiúscula na linha pertencem a um mesmo grupo, de acordo com o critério de agrupamento de Scott-Knott (1974), a 5\% de probabilidade.

${ }^{2}$ Médias seguidas de mesma letra minúscula, em cada coluna, não diferem entre si pelo teste F, a 5\% de probabilidade. 
TABELA 5. Conteúdo de isoflavonas nas sementes de seis cultivares de soja cultivadas em Maringá e Umuarama - PR, no ano agrícola de 2004/2005. Continuação...

\begin{tabular}{|c|c|c|c|c|c|c|}
\hline \multirow[b]{2}{*}{ Maringá } & \multicolumn{6}{|c|}{ Genistina (mg. 100g-1 de farinha) } \\
\hline & $6,94 \mathrm{Ba}$ & $10,65 \mathrm{Ab}$ & $11,43 \mathrm{Ab}$ & $9,16 \mathrm{Ba}$ & $13,57 \mathrm{Aa}$ & $12,22 \mathrm{Aa}$ \\
\hline Umuarama & $8,18 \mathrm{Da}$ & $17,44 \mathrm{Aa}$ & $15,29 \mathrm{Ba}$ & $10,76 \mathrm{Ca}$ & $15,39 \mathrm{Ba}$ & $13,69 \mathrm{Ba}$ \\
\hline Média & 7,56 & 14,04 & 13,36 & 9,96 & 14,48 & 12,95 \\
\hline \multirow[t]{2}{*}{ C.V. $(\%)$} & 12,68 & & & & & \\
\hline & \multicolumn{6}{|c|}{ Malonil Daidzina (mg. $100 \mathrm{~g}^{-1}$ de farinha) } \\
\hline Maringá & $32,80 \mathrm{Ca}$ & $72,67 \mathrm{Aa}$ & $63,50 \mathrm{Ab}$ & $51,57 \mathrm{Ba}$ & $50,29 \mathrm{Ba}$ & $70,04 \mathrm{Aa}$ \\
\hline Umuarama & $31,92 \mathrm{Da}$ & $60,07 \mathrm{Bb}$ & 78,74 Aa & $46,50 \mathrm{Ca}$ & $48,78 \mathrm{Ca}$ & $62,23 \mathrm{Ba}$ \\
\hline Média & 32,36 & 66,37 & 71,12 & 49,03 & 49,53 & 66,13 \\
\hline \multirow[t]{2}{*}{ C.V. $(\%)$} & 12,33 & & & & & \\
\hline & \multicolumn{6}{|c|}{ Malonil Glicitina (mg. $100 \mathrm{~g}^{-1}$ de farinha) } \\
\hline Maringá & 9,95 Ca & $32,40 \mathrm{Aa}$ & $23,95 \mathrm{Aa}$ & $28,97 \mathrm{Aa}$ & $19,40 \mathrm{Ca}$ & $21,60 \mathrm{Ba}$ \\
\hline Umuarama & $9,89 \mathrm{Ba}$ & $20,31 \mathrm{Ab}$ & $23,80 \mathrm{Aa}$ & $16,19 \mathrm{Bb}$ & $15,15 \mathrm{Ba}$ & $13,87 \mathrm{Bb}$ \\
\hline Média & 9,96 & 26,35 & 23,87 & 22,58 & 17,27 & 17,73 \\
\hline \multirow[t]{2}{*}{ C.V. (\%) } & 22,39 & & & & & \\
\hline & \multicolumn{6}{|c|}{ Malonil Genistina (mg. $100 \mathrm{~g}^{-1}$ de farinha) } \\
\hline Maringá & $25,24 \mathrm{Da}$ & $37,32 \mathrm{Bb}$ & $42,84 \mathrm{Ab}$ & $33,16 \mathrm{Ca}$ & $43,47 \mathrm{Aa}$ & $46,39 \mathrm{Aa}$ \\
\hline Umuarama & $19,77 \mathrm{Db}$ & $50,67 \mathrm{Aa}$ & $51,14 \mathrm{Aa}$ & $34,36 \mathrm{Ca}$ & 39,99 Ba & $42,57 \mathrm{Ba}$ \\
\hline Média & 22,50 & 43,99 & 46,99 & 33,76 & 41,73 & 44,48 \\
\hline C.V. (\%) & 10,23 & & & & & \\
\hline
\end{tabular}


TABELA 6. Coeficientes de correlação simples de Pearson (r) estimados entre os resultados de produtividade, massa de mil sementes, testes que avaliaram a qualidade fisiológica das sementes e os teores de óleo e proteínas com o teor total de isoflavonas e as suas diferentes formas encontradas nas sementes de soja produzidas em Maringá PR, no ano agrícola de 2004/2005.

\begin{tabular}{|c|c|c|c|c|c|c|c|}
\hline Varáveis & Isoflavomas & Daidzina & Glicitina & Genistina & $\begin{array}{l}\text { Malomil } \\
\text { daidzina }\end{array}$ & $\begin{array}{l}\text { Malonil } \\
\text { glicitina }\end{array}$ & $\begin{array}{l}\text { Malonil } \\
\text { genistina }\end{array}$ \\
\hline Produtividade & $0,00^{\mathrm{in}}$ & $0,35^{*}$ & $0,25^{\text {na }}$ & $-0,23^{=1}$ & $0,02^{\mathrm{res}}$ & $-0,08^{m}$ & $-0,19^{=1}$ \\
\hline Massa de nil sementes & $-0,55 *$ & $-0,46^{*}$ & $-0,61^{*}$ & $-0,33 *$ & $-0,46 *$ & $-0,45^{*}$ & $-0,44^{*}$ \\
\hline Phimeira contagem & $-0,24^{\mathrm{min}}$ & $-0,24^{\mathrm{m}}$ & $-0,07^{ \pm a}$ & $-0,19^{m}$ & $-0,23^{\mathrm{res}}$ & $-0,10^{\mathrm{m}}$ & $-0,26=$ \\
\hline Geminação & $-0,08^{\min }$ & $-0,12^{\mathrm{m}}$ & $0,05^{\mathrm{na}}$ & $-0,06^{=}$ & $-0,10^{\mathrm{r}}$ & $0,00^{\mathrm{re}}$ & $-0,12=$ \\
\hline Vigcr & $-0,10^{\mathrm{min}}$ & $0,04^{\mathrm{rx}}$ & $0,07^{ \pm 0}$ & $-0,34^{=1}$ & $-0,05^{\mathrm{r}}$ & $0,12^{\mathrm{n}}$ & $-0,45^{*}$ \\
\hline Viabilidade & $-0,21^{18}$ & $-0,23^{\mathrm{ma}}$ & $-0,33^{*}$ & $-0,22^{\mathrm{s}}$ & $-0,13^{\mathrm{m}}$ & $0,02^{\mathrm{n}}$ & $-0,38^{n}$ \\
\hline Óleo & $0,10^{\mathrm{min}}$ & $-0,05^{\mathrm{m}}$ & $0,14^{\mathrm{ma}}$ & $0,06^{=}$ & $0,08^{\mathrm{res}}$ & $0,04^{\mathrm{m}}$ & $0,21^{\mathrm{me}}$ \\
\hline Proteinas & $0,08^{\mathrm{na}}$ & $0,10^{\text {ne }}$ & $0,07^{\mathrm{na}}$ & $-0,02^{\mathrm{m}}$ & $0,15^{\mathrm{re}}$ & $-0,03^{\mathrm{rn}}$ & $0,03^{\text {mi }}$ \\
\hline
\end{tabular}

* Significativo a $5 \%$ de probabilidade.

${ }^{m}$ Não significativo.

TABELA 7. Coeficientes de correlação simples de Pearson (r) estimados entre os resultados de produtividade, massa de mil sementes, testes que avaliaram a qualidade fisiológica das sementes e os teores de óleo e proteínas com o teor total de isoflavonas e as suas diferentes formas encontradas nas sementes de soja produzidas em Umuarama, PR, no ano agrícola de 2004/2005.

\begin{tabular}{|c|c|c|c|c|c|c|c|}
\hline Vaniáveis & Isoflavonas & Daidzina & Glicitina & Genistina & $\begin{array}{l}\text { Malonil } \\
\text { daidzina }\end{array}$ & $\begin{array}{l}\text { Malonil } \\
\text { glicitina }\end{array}$ & $\begin{array}{l}\text { Malonil } \\
\text { gemistina }\end{array}$ \\
\hline Produtividade & $0,16^{=m}$ & $0,08^{\text {th }}$ & $-0,02^{\text {min }}$ & $0,06^{\mathrm{mi}}$ & $0,12^{\text {min }}$ & $0,28^{\text {ma }}$ & $0,20^{\mathrm{min}}$ \\
\hline Massa de nil sementes & $-0,69 *$ & $-0,35 *$ & $-0,30 *$ & $-0,45^{*}$ & $-0,73 *$ & $-0,73 *$ & $-0,64^{*}$ \\
\hline Primeira contagem & $0,55^{*}$ & $0,31^{\text {ta }}$ & $0,33^{*}$ & $0,53 *$ & $0,45^{\mathrm{m}}$ & $0,66^{*}$ & $0,56^{*}$ \\
\hline Germinação & $0,57 *$ & $0,36 *$ & $0,38^{*}$ & $0,51^{*}$ & $0,46^{\mathrm{ms}}$ & $0,68 *$ & $0,57^{*}$ \\
\hline Vigor & $0,19=$ & $0,05^{\mathrm{ma}}$ & $0,13^{\text {min }}$ & $0,11^{\mathrm{ms}}$ & $0,19^{\mathrm{ms}}$ & $0,39 *$ & $0,15^{\mathrm{mi}}$ \\
\hline Viabilidade & $0,19=$ & $0,04^{\mathrm{ma}}$ & $0,11^{\mathrm{ma}}$ & $0,16^{\mathrm{ms}}$ & $0,20^{\mathrm{m}}$ & $0,38^{*}$ & $0,14^{1 \mathrm{~m}}$ \\
\hline Óleo & $0,05=$ & $0,01^{\text {mat }}$ & $-0,02^{\mathrm{min}}$ & $-0,00^{\mathrm{ns}}$ & $0,05^{\mathrm{ms}}$ & $0,23^{\mathrm{ma}}$ & $-0,01^{\mathrm{min}}$ \\
\hline Proteinas & $-0,46^{*}$ & $-0,08^{\text {tat }}$ & $0,11^{\mathrm{ma}}$ & $-0,23^{\mathrm{mat}}$ & $-0,57 *$ & $-0,39 *$ & $-0,52^{*}$ \\
\hline
\end{tabular}


concordando com os resultados obtidos por Allen et al. (2004). Contudo, o mesmo resultado não foi observado em Umuarama (Tabela 7).

Quanto a correlação entre os testes utilizados para determinar a qualidade fisiológica das sementes e o teor de isoflavonas totais e suas formas glicosil e malonil, notou-se, pela análise das Tabelas 6 e 7, que em Maringá o teor total de isoflavonas não se correlacionou com os referidos testes, embora em Umuarama tenha havido correlação significativa e positiva entre os testes de germinação e primeira contagem da germinação.

\section{CONCLUSÕES}

- As sementes de todas as cultivares semeadas em Maringá apresentaram germinação superior a $80 \%$, enquanto que para Umuarama somente as cultivares EMBRAPA 48 e BRS 133.

- o teor de isoflavonas diferiu apenas entre os diferentes genótipos de soja, tanto em Maringá como em Umuarama o teor de isoflavonas totais das sementes produzidas foi maior para as cultivares EMBRAPA 48 e BRS 133 e menor para a cultivar BR 36.

- a massa de mil sementes apresentou correlação negativa com o teor de isoflavonas totais e com as formas de isoflavonas em ambos locais de semeadura.

\section{REFERENCIAS}

ALLEN, F.L.; CHARRON, C.S.; JOHNSON, R. D.; SAMS, C.E. Associations between isoflavones and protein content in soybean (Glycine max) seed. Euphytica. Dordrecht, v.138, n.1, p.55-60, 2004.

ASSOCIATION OF OFFICIAL ANALYTICAL CHEMISTS, A.O.A.C. Official methods of analysis. Washington, 1975. 1054p.

BANZATTO, D.A.; KRONKA, S.N. Experimentação Agrícola. 3. ed. Jaboticabal, FUNEP, 1992. 247p.

BENZAIN, B.; LANE, P.W. Protein concentration of grains in relation to some weather and soil factors during 17 years of English winter-wheat experiments. Journal of the Science of Food and Agriculture, Londres, v.37, p. 435-444, 1986.

BERHOW, M.A. Modern analytical techniques for flavonoid determination.In: BUSLIG, B.S.; MATHEY, J.A. (ed.). Flavonoids in the living cell. New York: Klusher Academic, 2002. p.61-76
BORDIGNON, J.R.; LONG, S.P.; ENGESETH, N.J. Influência da composição atmosférica no comportamento da cultura da soja. In: CONGRESSO BRASILEIRO DE SOJA, 4, Londrina, Anais..., Paraná: Empresa brasileira de pesquisa agropecuária, p. 70-73. 2006.

BRASIL. Ministério da Agricultura e da Reforma Agrária. Regras para análise de sementes. Brasília: SNDA/DNDV/CLAV, 1992. 365p.

CALDWELL, C.R.; BRITZ, S.J.; MIRECKI, R.M. Effect of temperature, elevated carbon dioxide, and drought during seed development on the isoflavone content of dwarf soybean [ Glycine max (L.) Merrill] grown in controlled environments. Journal of Agricultural and Food Chemistry, Washington, v. 53, n. 4, p. 1125-1129, 2005.

CARRÃO-PANIZZI, M.C. Isoflavonóides em soja (Glycine max (L) Merril): variabilidade genética e ambiental de cultivares e efeito no processamento do extrato solúvel. Londrina: UEL, 1996. 123p. (Tese Doutorado).

CARRÃO-PANIZZI, M.C., FAVONI, S.P.G.; KIKUCHI, A. Extraction time for isoflavone determination. Brasilian Archives of Biology and Technology, Curitiba, v.45, n.4, p.515-518, Dec.2002.

CARRÃO-PANIZZI, M.C.; SIMÃO, A.S.; KIKUCHI, A. Efeitos de genótipos, ambientes e de tratamentos hidrotérmicos na concentração de isoflavonas agliconas em grãos de soja. Pesquisa Agropecuária Brasileira, Brasília, v.38, n.8, p.897-902, 2003.

CARRÃO-PANIZZI, M.C.; KITAMURA, K. Isoflavone content in Brazilian soybean cultivars. Breeding Science, Tokyo, v.45, n.3, p.295-300, 1995.

CARRÃO-PANIZZI, M.C.; KITAMURA, K.; BELÉIA, A.D.P.; OLIVEIRA, M.C.N. Influence of growth locations on isoflavone contents in Brazilian soybean cultivars. Breeding Science, Tokyo, v.48, p.409-413, 1998.

CHOI, J.S.; KWON, T.W.; KIM, J.S. Isoflavone contents in some varieties of soybean. Journal Korea Foods and Biotechnology, Seoul, v.5, n.2, p.167-169, 1996.

COSTA, N.P.; PEREIRA, L.A.G.; FRANÇA NETO, J.B.; HENNING, A.A. Zoneamento ecológico do Estado do Paraná para a produção de sementes de cultivares precoces de soja. Londrina: EMBRAPACNPSo, 1992. 28p. (Boletim de Pesquisa, 2).

DAYDÉ, J.; LACOMBE, S. Variation of isoflavone content and composition in soybean seeds an related products. In: INTERNATIONAL SOYBEAN PROCESSING AND UTILIZATION CONFERENCE, 3., 2000, Tsukuba. Proceedings... Tsukuba: The Japanese Society for Food Science and Technology, 2000. p.55-58.

DELOUCHE, J.C. Physiological changes during storage that affect soybean seed quality. In: SINCLAIR, J.B.; JACKOBS, J.A. (ed.). Soybean seed quality and stand establishment. s.l.: Intsoy, 1982. p.57-66. (Intsoy, 22). 
ELDRIDGE, A. Determination of isoflavones in soybean flours, protein concentrates, and isolates. Journal of Agricultural and Food Chemistry, Washington, v.30, n.2, p.353-355, 1982.

EMBRAPA. Sistema brasileiro de classificação dos solos. Embrapa, Brasília, 1999.412p.

EMBRAPA SOJA. Tecnologias de produção de soja - Paraná - 2003. Londrina: Embrapa Soja, 2002. 195p. (Sistemas de Produção, 2).

FAGERIA, N.K. Solos tropicais e aspectos fisiológicos das culturas. 1. ed. Brasília: Departamento de Publicações EMBRAPA-CNPAF, 1989. p.381-392.

FEHR, W.R.; CAVINESS, C.E.; GURMOOD, D.T.; PENNINGTON, J.S. Stage of development description for soybean, Glycine max (L.) Merrill. Crop Science, Madison, v.11, n.6, p.929-931, 1971.

FRANÇA NETO, J. B.; KRZYZANOWSKI, F.C.; COSTA, N.P.; HENNING, A.A. O teste de tetrazólio em sementes de soja. Londrina: EMBRAPA-CNPSo, 1998. 72p. (EMBRAPA-CNPSo. Documentos, 116).

FRANÇA NETO, J.B.; KRZYZANOWSKI, F.C.; COSTA, N.P. Metodologia do teste de tetrazólio em sementes de soja. In: KRZYZANOWSKI, F. C.; VIEIRA, R. D.; FRANÇA NETO, J. B. (eds.). Vigor de sementes: conceitos e testes. Londrina: ABRATES, 1999. Cap.8.5, p.1-28.

FRANÇA NETO, J.B.; HENNING, A.A. Qualidade fisiológica e sanitária de sementes de soja. Londrina: EMBRAPA-CNPSo, 1984.39p. (Circular Técnica, 9).

FUKUTAKE, M.; TAKAHASHI, M.; ISHIDA, K.; KAWAMURA, H.; SUGIMURA, T.; WAKABAYASHI, K. Quantification of genistein and genistin in soybeans and soybean products. Food and Chemical Toxicology, v.34, n.5, p.457-461, 1996.

HARRIS, H.C.; McWILLIAM, J.R.; MASON, W.K. Influence of Temperature on Oil Content and Composition of Sunflower Seed. Australian Journal of Agricultural Research, Collingngwood, v. 29, n.3, p.1203-1212, 1978.

IAPAR. Cartas climáticas básicas do Estado do Paraná. Londrina: Instituto Agronômico do Paraná, 1987. 35p.

INSTITUTO ADOLFO LUTZ. Normas analíticas do Instituto Adolfo Lutz; métodos químicos e físicos para analise de alimentos. São Paulo, v.1, 1985. p.533.

KEIGLEY, P.J.; MULLEN, R.E. Changes in soybean seed quality from high temperature during seed fill and maturation. Crop Science, Madison, v.26, n.5, p.1212-1216, 1986.

KITAMURA, K.; IGITA, K.; KIKUCHI, A.; KUDOU, S.; OKUBO, $\mathrm{K}$. Low isoflavone content in early maturing cultivars, so called summer-type soybeans (Glycine max (L.) Merrill). Japanese Journal of Breeding, Ikushugakuzasshi, v.41, p.651-654, 1991.

KUDOU, S.; FLEURY, Y; WELTI, D.; MAGNOLATO, D.; UCHIDA, T.; KITAMURA, K., OKUBO, K. Malonil isoflavone glycosides in soybeans seeds (Glycine max Merril). Agriculture and Biology Chemistry, Tokyo, v.55, p. 2227-2233, 1991.
KRZYZANOWSKI, F.C.; WEST S.H. FRANÇA NETO, J.B. Influência do conteúdo de isoflavonas sobre a qualidade fisiológica da sementes de soja. In: CONGRESSO BRASILEIRO DE SEMENTES, 7. Anais... Londrina: Embrapa - CNPSo, 2001. p.47.

MOTTA, I.S.; BRACCINI, A.L.; SCAPIM, C.A.; GONÇALVES, A.C.A.; BRACCINI, M.C.L. Características agronômicas e componentes da produção de sementes de soja em diferentes épocas de semeadura. Revista Brasileira de Sementes, Brasília, v.22, n.2, p.257-267, 2000.

PARANÁ. Secretaria de Estado da Agricultura. Normas de produção de sementes, básica, registrada, certificada e fiscalizada. Curitiba: Empresa Paranaense de Classificação de Produtos, 1986.

PARK, Y.K.; AGUIAR, C.L.; ALENCAR, S.M.; SCAMPARINI, A.R.P. Avaliação do teor de isoflavonas em soja Brasileira. Ciência e tecnologia de alimentos. V.3, n.3, p. 156-160, 2001.

PÍPOLO, A.E. Influência da temperatura sobre as concentrações de proteína e óleo em sementes de soja (Glycine max (L.) Merrill). Universidade de São Paulo: USP, Escola Superior de Agricultura "Luiz de Queiroz", 2002. 128p. (Tese Doutorado).

POPINIGIS, F. Fisiologia da semente. Brasília: Minitério da Agricultura/AGIPLAN, 1985.289p.

RAMALHO, M.A.P; FERREIRA, D.F.; OLIVEIRA, A.C. A experimentação em genética e melhoramento de plantas. UFLA: Lavras, 2000. p.114-134.

RANGEL, M.A.S.; CAVALHEIRO, L.R.; CAVICHIOLLI, D.; CARDOSO, P.C. Efeito do genótipo e do ambiente sobre os teores de óleo e proteína nos grãos de soja, em quatro ambientes da região sul de Mato Grosso do Sul, safra 2002/2003. (Boletim de pesquisa e desenvolvimento 17), Embrapa, Dourados, 2004.

RAO, A.C.S.; SMITH, J.L.; V.K.; JANDHYALA, R.I.; PARR, J.F. Cultivar and climatic effects on the protein content of soft white winter wheat. Agronomy Journal, Madison, v.85, p.1023-1028, 1993.

SEDIYAMA, T.; PEREIRA, M.G.; SEDIYAMA, C.S.; GOMES, J.L.L. Cultura da Soja, Parte I. UFV, Minas Gerais, 97p. 1993.

SCOTT, A.; KNOTT, M. Cluster-analysis method for grouping means in analysis of variance. Biometrics, Washington D.C., v.30, p.507-512, 1974.

SHAFFI, B.; MAHLER, K.A.; PRICE, W.J.; AULD, D.L. Genotype $\mathrm{x}$ environment interaction effects on winter rape seed yield and oil content. Crop Science, Madison, v.32, p.922-927, 1992.

SHAHIDI, F.; WANASUNDARA, P.K.J.P.D. Pnenolic antioxidants. Critical Reviews in Food Science and Nutrition, v.32, n.1, p.67-103, 1992.

SINGH, R.B.; WILLIAMS, P.C.; NAKKOUL, H. Influence of g rowing season, location and planting time on some quality parameters of Kabuli chickpea. Jornal of Science of Food Agricultural, Londres, v.15, p.429-441, 1990. 
TAIZ, L.;ZEIGER, E. Trad.: SANTARÉM, E.R. Fisiologia vegetal. 3a. ed. Porto Alegre:Artmed, p.613. 2004.

TEKRONY, D.M.; EGLY, D.B.; PHILLIPS, A.D. Effects of field weathering on the viability and on vigor of soybean seed. Agronomy Journal, Madison, v.72, n.5, p.749-753, 1980.

TSUKAMOTO, C.; SHIMADA, S.; IGITA, K.; KUDOU, S.; KOKUBUN, M.; OKUBO, K.; KITAMURA, K. Factors affecting isoflavone content in soybean seeds: changes in isoflavones, saponins, and composition of fatty acids at different temperatures during seed development. Journal of Agricultural and Food Chemistry, Washington, v. 43, p.1184-1192, 1995.

VIEIRA, L.R.D.; SEDIYAMA, T.; SILVA, R.F.; SEDIYAMA, C.S.; THIEBANT, J.T.L.; XIMENES, P.A. Estudo da qualidade fisiológica de semente de soja (Glycine max (L.) Merrill) cultivar UFV-1 em quinze épocas de colheita. In: SEMINÁRIO NACIONAL DE PESQUISA DE SOJA, 2. Brasília, 1981. Anais..., Londrina: EMBRAPA-CNPSo, 1982. v.1, p.633-644.

WANG, H.; MURPHY, P.A. Isoflavone Content in Commecial Soybean Foods. Journal of Agriculture Food Chemistry, Washington, v.42, p.1666-1673, 1994.

WILCOX, J.R.; CAVINES, J.F. Normal and low lenolenic acid soybean strains. Response to planting date. Crop Science, Madison, v.32, p.1248-1251, 1992.

YIN, X.; VYN, T.J. Relationships of Isoflavone, Oil, and Protein in Seed with Yield of Soybean. Agronomy Journal, Madison, v.97, p.1314-1321, 2005. 